\title{
Commentary on Facial Rejuvenation with Fine Barbed Threads: The Simple MIZ-Lift
}

\author{
Woffles T. L. Wu
}

Received: 31 October 2013/ Accepted: 5 November 2013/Published online: 18 January 2014

(C) Springer Science+Business Media New York and International Society of Aesthetic Plastic Surgery 2014

Level of Evidence $V$ This journal requires that authors assign a level of evidence to each article. For a full description of these Evidence-Based Medicine ratings, please refer to the Table of Contents or the online Instructions to Authors www.springer.com/00266.

I am delighted to write a commentary on this paper by Park and colleagues. It is a useful contribution to the body of work published about barbed threads in nonsurgical facial rejuvenation, further validating their use as a viable alternative to surgical face-lifting.

The authors have presented an elegant technique of thread-lifting that involves first partial dissection in the temporal region and then closed insertion of their modified MIZ threads into the distal part of the face, with the deep temporal fascia providing a stable fixation point for the threads.

The results, although subtle, are pleasing and harmonious, with elevation of the cheek/jowl area and volume restoration in the midcheek region. However, the latter may be difficult to assess because nearly $80 \%$ of patients undergoing the MIZ-lift also had autologous fat grafting at the same time. I would have preferred a comparison between a series of patients who had only the thread-lifting procedure and nothing else.

I agree with the authors that the ideal material for a thread-lift is a nonabsorbable prolene suture correctly inserted, which elicits a fibrous capsular contraction around the threads that in turn adds to the longevity and stability of the result. With absorbable threads, the holding power is questionable because the barbs are the smallest part of the

W. T. L. Wu ( $\square)$

Camden Medical Centre, 1 Orchard Boulevard, Suite 09-02,

Singapore 294615, Singapore

e-mail: woffles@woffleswu.com thread and likely to dissolve first, thus giving very shortterm results. Of course, if the insertion technique is imprecise or performed in the wrong planes or vectors, then it is better that the thread dissolves in time so as not to give any long-lasting complications.

The technique described by the authors is not dissimilar in concept to the Woffles Lift [1-3] I pioneered in 2002 or the Isse endo-thread-lift [4] developed by Nicanor Isse in 2004.

By way of historical background [5], although barbed sutures were conceptualized years ago by Alcamo [6, 7], Fukuda [8], Ruff [9, 11] and Buncke [10] for knotless wound closure or tendon repair, all credit must go to $\mathrm{Su}-$ lamanidze [12, 13], who first pioneered the use of bidirectional threads in facial cosmetic applications. His APTOS procedure was novel, unique, and effective, with many surgeons still using it worldwide, including this author.

However, I felt that the APTOS procedure, which is essentially a grid of short barbed sutures with no stable fixation point, gave more of a face-firming than a facelifting effect. Therefore, in 2002 I developed my own bidirectional barbed suture slings that were folded on themselves and had a stable fixation point in the deep temporal fascia. This arrangement conferred greater lifting power and a higher pullout tension, which has been verified by independent researchers [14]. I thought that with this stronger version of a long looped barbed suture, it was more logical to suspend the loose facial tissues to the dense and immovable fibrous temporal fascia. I was therefore able to achieve more significant lifting of soft tissues that lasted longer and initially called it the WAPTOS (WofflesAPTOS) procedure in acknowledgement of Sulamanidze's APTOS procedure.

However, after Sulamanidze saw me present my initial results at the International Confederation of Plastic and 

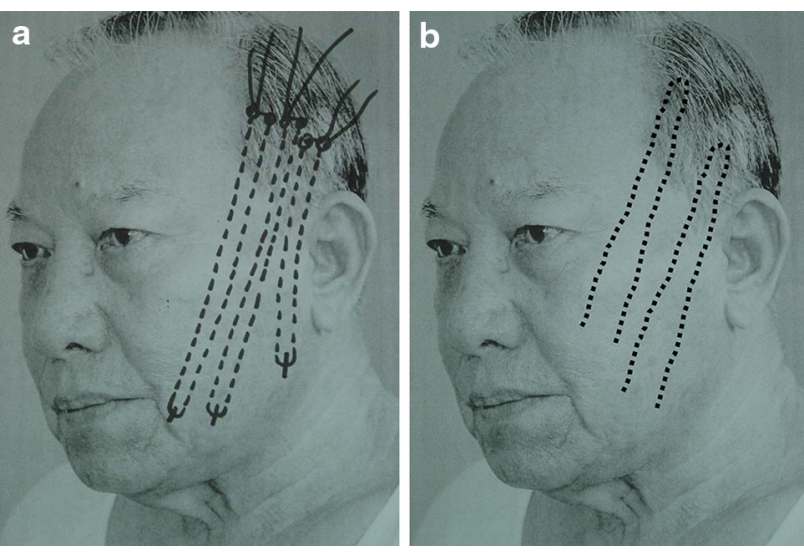

Fig. 1 a Woffles Lift Version 1 showing the loops of the threads in the distal face and their free ends tied subcutaneously in the temple. b Woffles Lift Version 2 showing an inverse orientation of the threads, with the loop in the temple and the free ends in the distal face

Reconstructive Surgery (IPRAS) meeting in Sydney, Australia in September 2003 [15], he encouraged me to use my own name because the method of application was different from his APTOS technique. Thus the name of my technique was changed to the Woffles Lift, and the suture was called the Woffles thread.

Isse also was in the audience at this presentation. He was inspired to make his own version of a monodirectional barbed thread anchored at the temple via a surgical approach and to use it in conjunction with the endoscopic face-lift technique he had developed. We subsequently presented our respective results in a panel discussion at the Annual American Society of Aesthetic Plastic Surgeons meeting in Vancouver, 2004. Isse's thread design was later acquired by the Contour Thread Company.

With the Woffles Lift Version 1, the loop of the sling was in the distal face, and the two free ends were tied together at the temple (Fig. 1a). This occasionally gave rise to knot palpability or extrusion. I then decided to invert the suture slings such that the loop of the sling would be embedded superiorly in the temporal fascia, with the free ends of the thread oriented distally (Fig. 1b). This conferred better lifting of the soft tissues in the lower face and avoided the need to tie any knots. It was more effective and had a lower complication rate $(\sim 2 \%)$. Currently, it is called the Woffles Lift Version 2, and I have been using it since 2004. Since then, I have not encountered any problems of granuloma, infection, or thread extrusion.

The MIZ-lift uses my concept of a stable fixation point at the temporal fascia but has more similarity to Isse's technique in that they both use a surgical dissection at the temple, separation of superficial and deep tissue planes, insertion of the threads, and suture of the threads down to the deep temporal fascia.

My own preference has been to use the Woffles Lift as a totally nonsurgical method to achieve face-lifting and not
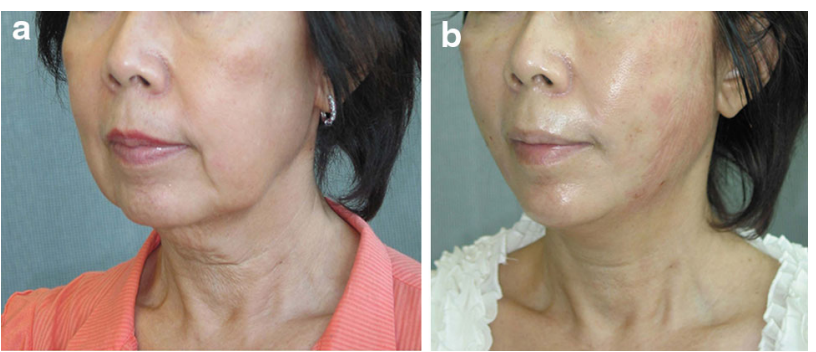

Fig. 2 a Preoperative view of a 59-year-old woman who wanted a face-lift without surgery and with minimal downtime. b Postoperative view 4 days after Woffles Lift Version 2 showing triangulation and rejuvenation of the lower face, with only some needle marks and redness that can be easily covered up by makeup
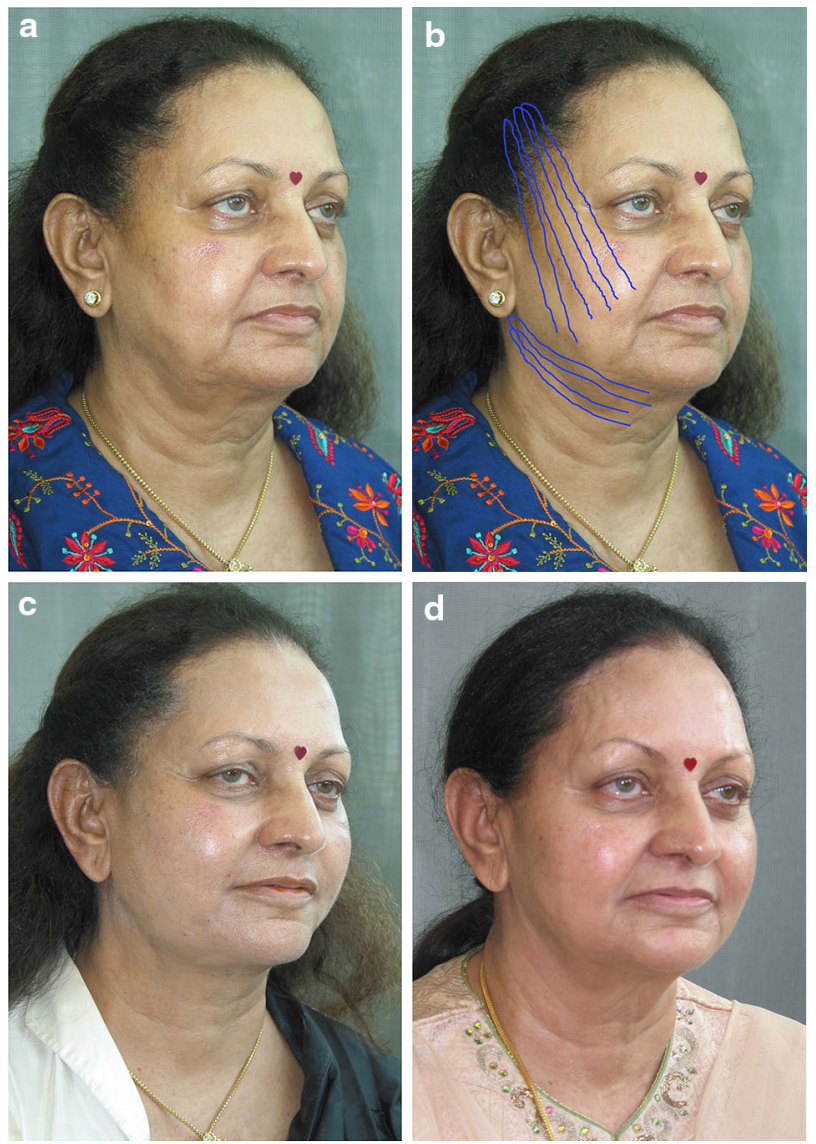

Fig. 3 a Preoperative view of a 60-year-old woman wanting significant face and neck rejuvenation without surgery. b Preoperative view showing markings of the Woffles Lift of the face and neck. c Postoperative view 1 week after the procedure. The patient is able to resume social activities. d Postoperative view 5 years after the initial procedure

to add any surgical components to it (Fig. 2a, b). Consequently, this appeals to patients reluctant to have surgery for whatever reason who want a shorter downtime and a faster recovery (Fig. 3a-d). 
The Woffles Lift is performed with the patient sitting upright. First, the face is numbed using Elamax $5 \%$ topical cream (Ferndale Laboratories, Ferndale, MI), and then anesthetic solution is infiltrated using the microanesthesia technique I described in 2007 [16]. The basis for the significant tissue elevation despite the absence of surgical delamination of planes with this technique can be attributed to the presence of the middle and lower premasseteric spaces described by Mendelson and coworkers [17]. These spaces act as natural glide planes between superficial and deeper tissues, allowing them to slide one on top of the other. Therefore, dissection is not essential to the achievement of face-lifting or redraping of soft tissues, although it is thought to be important for the longevity of results because the tissue planes presumably adhere in their new relationship with one another. Even then, however, we often see a relapse of marionette lines, nasolabial folds, and jowling as early as 1 year after a surgical face-lift, which can be quite disappointing for both the patient and the surgeon. This only indicates that delamination of soft tissue planes and readhesion alone are not sufficient to overcome the ongoing multiple forces of facial aging that conspire to thwart our rejuvenative efforts. Park and colleagues did not indicate in their paper how long the results of their MIZ thread-lift were expected to last.

Occasionally, I supplement the thread-lift with Botox in the glabellar, brow, and lateral orbital regions or with a hyaluronic acid filler to fill out aging hollows of the face. However, the composite result (which is part of my $4 R^{2}$ approach) still remains strictly nonsurgical. Thus, we can more clearly compare surgical with nonsurgical results, getting a sense of their respective effectiveness and longevity.

I commend the authors for their technique and for their reinforcement of the fact that facial soft tissue elevation can be accomplished in more ways than with surgery alone.

Disclosure The author declares that he owns patents for the design of the Woffles Threads but has not commercialized them in any way.

\section{References}

1. Wu WTL (2004) Barbed sutures in facial rejuvenation: APTOS threads and the Woffles Lift. Aesthet Surg J 24:582-587

2. Wu W (2006) Innovative uses of Botox and the Woffles Lift, chap 72. In: Panfilov D (ed) Aesthetic surgery of the facial mosaic. Springer, Berlin, pp 636-649

3. Wu W (2013). Non surgical facelifting with long barbed suture slings. J Aesthet Chir 1

4. Isse N, Fodor PB (2005) Elevating the midface with barbed polypropylene sutures. Aesthet Surg J 25:301-303

5. Kress DW (2008) The history of barbed suture suspension: applications and visions for the future, Chap. 33. In: Shiffman MA, Mirrafati SJ, Lam SM (eds) Simplified facial rejuvenation. Springer, New York, pp 247-256

6. Alcamo JH (1961) Surgeon's suturing device. US patent $2,988,028$

7. Alcamo JH (1964) Surgical suture. US patent $3,123,077$

8. Fukuda (1984) Surgical barbed suture. US patent $4,467,805$

9. Ruff GL (1994) Insertion device for a barbed tissue connector. US patent 5,342,376

10. Buncke HJ (1999) Surgical methods using one-way suture. US patent $5,931,855$

11. Ruff GL (2001) Barbed bodily tissue connector. US patent $6,241,747 \mathrm{~B} 1$

12. Sulamanidze MA, Fournier PF, Paikidze TG, Sulamanidze GM (2002) Removal of facial soft tissue ptosis with special threads. Dermatol Surg 28:367-371

13. Sulamanidze MA, Sulamanidze GM (2005) Facial-lifting with "APTOS" threads: featherlift. Otolaryngol Clin North Am 8:1109-1117

14. Sasaki GH, Komorowska-Timek ED, Bennett DC, Gabriel A (2008) An objective comparison of holding, slippage, and pullout tensions for eight suspension sutures in the malar fat pads of fresh-frozen human cadavers. Aesthet Surg J 28:387-396

15. Wu WTL (2003) Facial rejuvenation using APTOS and WAPTOS (the Woffles lift): a novel approach. In: 13th International Congress of the International Confederation of Plastic and Reconstructive Surgery (IPRAS), Sydney, Australia, 10-14 September 2003

16. Wu WTL (2007) Achieving optimal results with thermage using mesoanaesthesia and revised treatment protocols. Aesthet Surg J 1:93-99

17. Mendelson BC, Freeman ME, Wu W, Huggins RJ (2008) Surgical anatomy of the lower face: The premasseter space, the jowl, and the labiomandibular fold. Aesthet Plast Surg 32:185-195 